\title{
AKTIVITI MELUKIS MENINGKATKAN KEYAKINAN DIRI DALAM KALANGAN KANAK-KANAK
}

\author{
Effetiveness of Drawing Activity in Increasing Confidence among Children
}

\author{
Norjietta Julita Taisin \\ Fakulti Bahasa dan Komunikasi \\ Universiti Pendidikan Sultan Idris \\ Tanjong Malim, Perak, Malaysia \\ norjietta@fbk.upsi.edu.my
}

\begin{abstract}
ABSTRAK
Keupayaan menghasilkan karya seni dalam kalangan kanak-kanak merupakan interaksi secara tidak langsung mereka dengan alam sekeliling serta dapat mengembangkan keupayaan mereka dalam membuat tafsiran melalui persekitaran mereka. Hasil seni merupakan penjelmaan beberapa bahagian nilai dan sikap. Oleh itu untuk melaksanakannya harus melihat keberkesanan aktiviti melukis dalam meningkatkan keyakinan diri dalam kalangan kanak-kanak. Huraian ini diketengahkan dengan menggunakan reka bentuk kualitatif untuk mengumpul data iaitu melalui pemerhatian dalam kelas, pemerhatian penilaian hasil kerja seni dan alatan bahan yang digunakan oleh kanak-kanak dalam karya seni mereka. Hasil kajian tersebut mendapati bahawa aktiviti melukis mampu mengimbangi hubungan komunikasi antara murid dengan rakan sebaya serta meningkatkan keyakinan diri kanak-kanak yang berterusan. Aktiviti melukis dapat memberi kepuasan kanak-kanak dalam meluahkan apa yang dilihat dan mereka pindahkan semula dalam bentuk dan rupa imej yang unik mengikut tahap pemahaman mereka. Justeru keyakinan diri terbina apabila kanak-kanak mampu melukis tanpa ragu-ragu dan tidak bimbang memikirkan soal kecantikan karya seni mereka. Melalui aktiviti melukis menggalakkan kanak-kanak untuk bercerita mengenai karya mereka dalam membina keyakinan diri untuk mereka bertutur dan seterusnya dapat meningkatkan sensitiviti pancaindera mereka.
\end{abstract}

Kata Kunci: karya seni, keyakinan diri, kanak-kanak, melukis dan sensitiviti.

\begin{abstract}
The ability to produce works of art among children is an indirect interaction with the environment and it can develop their capabilities in making interpretations through their environment. Artwork is the embodiment of the values and attitudes. Therefore, the effectiveness of drawing activity in raising the confidence level among children is analyzed. The explanation of this study is conducted by qualitative approach to collect data through observation in the classroom, the observation of artwork assessment and the materials used by children in their artwork. This study showed that the activity of drawing is able to keep communication between students with peers and enhance self-confidence among children and it is continued. Drawing can give satisfaction to children in expressing what they have seen and transfer it into shape and unique image according to their understanding. Therefore, as confidence level can develop as the child is able to draw without hesitation and worry about the beauty of their artwork. Through drawing activity, it encourage children to tell about their work in a way to raising their confidence to speak out and thus can increase the sensitivity of their senses.
\end{abstract}

Keywords: art, self-confidence, children, drawing and sensitivity 


\section{PENGENALAN}

Sebelum manusia menggunakan huruf, lukisan adalah merupakan alat utama untuk berkomunikasi antara satu sama lain. Mengamati dan mentafsir imej-imej tampak dengan menggunakan bahasa tampak yang lahir dari kecerdasan 'visual-visual-kreatif yang sentiasa wujud sentiasa wujud dan membantu secara berkesan pada setiap peringkat interprestasi dan penyataan apabila berhadapan dengan imej-imej tertentu. Yakni, yang berlaku ketika itu ialah proses komunikasi tampak sosial non-verbal yang menggunakan bahasa tampak (Micheal, 1983).

Banyak kajian yang dijalankan bagi mengenal pasti kebolehan kanak-kanak. Aktiviti melukis dikatakan sebagai suatu bentuk aktiviti yang banyak digunakan oleh saintis, pendidik dan ibu bapa bagi menyelami perasaan dan fikiran kanak-kanak. Aktiviti melukis merupakan aktiviti yang membantu kanak-kanak mengenali objek selain membantu meningkatkan daya sensitiviti terhadap alam sekeliling mereka. Proses melukis yang menjurus ke arah pengamatan terhadap objek melatih deria kanak-kanak supaya menjadi lebih peka dan meningkatkan daya persepsi mereka.

Selain itu, aktiviti melukis juga meningkatkan daya imaginatif kanak-kanak selain berupaya mengimbangi emosi mereka. Ianya dijadikan sebagai satu proses pembelajaran kepada kanak-kanak melalui aktiviti imitasi alam sekeliling lalu dipermudahkan menjadi penghasilan simbol abstrak seterusnya menjadikan ia satu bentuk hasil karya yang unik.

Kehebatan sesuatu karya seni tampak tidak akan dapat dirasai jika hanya diberitahu secara lisan atau melalui tulisan. Justeru, aktiviti melukis merupakan pembelajaran awal kanak-kanak dalam meningkatkan proses kreativiti seni tampak dalam kalangan kanak-kanak kecil dan perkara ini diakui oleh pakar-pakar sains pemikiran kreatif seperti Amabile (1992), Buzan (2002), de Bono (1971), dan Leong (1998). Amabile (1992), menyifatkan bahawa institusi pendidikan, khususnya pendidikan prasekolah merupakan tempat paling penting untuk memupuk alam kreativiti dalam kalangan kanakkanak.

Cropley (2001) pula menegaskan bahawa pendidikan awal kanak-kanak sangat memerlukan persekitaran dan motivasi yang amat signifikan bagi merealisasikan bakat dan kemahiran kreativiti kanak-kanak. Selaras itu, Abd. Rahim (1999), menyatakan kreativiti amat penting dalam dunia pendidikan kerana ia mampu melahirkan sebuah citra masyarakat kreatif (creative society) dan negara kreatif (creative nation).

\section{TINJAUAN LITERATUR YANG BERKAITAN}

McFee (1962) menjelaskan bahawa di dalam sesuatu tamadun, sekiranya tidak wujud satu sistem simbol-simbol komunikasi yang berfungsi sebagai pengenalan status dan peranan yang boleh dikenal menerusi pakaian, artifak seperti perhiasan badan, seramik, fabrik dan sebagainya maka akan berlaku kekeliruan untuk mengenal maklumat yang menentukan siapa yang memegang sesuatu peranan tertentu. Oleh itu, aktiviti seni dalam pendidikan dapat memberi peluang kepada kanak-kanak untuk memperkembangkan potensinya dalam menghasilkan pengalaman baru hasil daripada penerokaan yang diperolehi dalam kehidupan seharian mereka.

Tidak dapat dinafikan bahawa melalui aktiviti seni dapat memainkan peranan ke arah perkembangan kanak-kanak melalui peningkatan kemahiran komunikasi sosial yang berkesan. Guru berinteraksi dengan murid untuk mengetahui tahap penguasaan murid terhadap aspek seni, kemahiran 
komunikasi dalam bahasa seni dan menilai potensi murid dalam kemahiran berfikir. Perkembangan daya kreatif dan mengenal pasti perlakuan emosi, perasaan dan perubahan sikap murid.

\section{Kajian-kajian yang berkaitan mengenai pengaruh aktiviti seni terhadap kanak-kanak dalam meningkatkan keyakinan diri.}

Victor Lownfeld dan Brittain (1986), telah meneliti lukisan kanak-kanak mengikut peringkat perkembangan kanak-kanak dan menerangkan bagaimana bahan kandungan subjek dan enviorment murid dapat disesuaikan mengikut peringkat perkembangan untuk merangsangkan pengutaraan tampak kanak-kanak, perkembangan kreatif dan mental seterusnya perkembangan menyeluruh kanak-kanak. Beliau turut menyarankan bahawa pengetahuan sedia ada boleh diaktifkan melalui cara-cara yang sesuai kepada perkembangan kanak-kanak. Antaranya menggunakan aksi kanak-kanak, objek yang konkrit, isi kandungan yang ada kaitan dengan kehidupan seharian diperingkat tersebut. Aktiviti seni memuaskan keperluan asas kanak-kanak dari segi fizikal, mental dan pertumbuhan yang sihat.

Menurut pensejarahan pendidikan seni Amerika Syarikat (Frederick Logan, 1975), seni amat berpengaruh terhadap kanak-kanak kerana ia menggalak mereka mengekspresikan diri mereka dalam usaha untuk memupuk disposes kreatif dan pemikiran umum mereka walaupun tidak semestinya dalam maksud signifikan. Gardner (1985), menyatakan bahawa 'Revolusi Kognitif' memberi pendekatan secara lebih revolusioner dalam memahami kegiatan dan penglibatan seni sebagai unsur kognitif.

Kegiatan seni khasnya melukis memberi impak yang amat positif terhadap perkembangan intelek kanak-kanak dalam meningkatkan keyakinan diri. Ini selaras dengan Donald W.Mac Kinnon (2005), menyatakan individu yang kreatif boleh menyatakan tentang dirinya di mana mempunyai aras intelektual yang tinggi dan berfikiran terbuka bagi mendapatkan pengalaman dan kepekaan estetika serta berdikari dalam aspek berfikir dan bertindak. Herman (1991) "Quadrant Concept” yang mengkaji perkembangan otak kanan dan otak kiri menyatakan bahawa seni membantu pemikiran rasional dan intuitif sesorang individu.

Selaras itu, Fox dan Diffily (2000), golongan profesional mengenal pasti akan kepentingan memberi peluang kepada kanak-kanak untuk perkembangan dalam sesebuah bidang, sosio-emosipsikomotor dan perkembangan kognitif. Seni lukis adalah penting sebagai penyemai perkembangan di peringkat awal kanak-kanak kerana itu Champman (1978:12), menyatakan bahawa kerja seni bukan sekadar suatu mod tingkahlaku semula jadi kanak-kanak tetapi adalah asas kepada matlamat kematangan. Idea bahawa pernyataan seni sebagai luahan emosi hasilan kerja seni sebagai alat untuk memahami corak psikologi kanak-kanak dan integrasi personaliti menerusi pengajaran seni telah menjadi slogan pengajaran seni di Amerika Syarikat menjelang sejak 1940an lagi.

Kajian Brown (1980), mendapati bahawa pengalaman kanak-kanak dalam memerhati ketika melukis atau membuat lakaran dapat meningkatkan kebolehan memperkayakan pengetahuannya tentang perbezaan-perbezaan setiap objek atau imej tampak di sekeliling mereka. Jika sekiranya kanakkanak diberi pendedahan kaedah dan teknik yang sempurna mereka akan berkeupayaan mengembangkan pemikiran yang kritis. Aktiviti seperti ini akan dapat mengembangkan naluri ingin tahu secara explorasi menerusi deria lalu melahirkan pemikiran kreatif dan kritis dan seterusnya dijana melalui ekspresi diri kanak-kanak.

Sementara itu, Efland (1977) dan Chapman (1978) menyatakan terdapat tiga tahap perkembangan proses artistik iaitu:

a. Mengumpul idea-idea 
b. Mengolah dan menjelmakan idea-idea tersebut dalam seni

c. Menggunakan media untuk menghasilkan kerja seni model untuk digunakan oleh muridmurid di dalam aktiviti-aktiviti artistik.

Oleh itu, tambah beliau berdasarkan kenyataan tersebut maka tindak balas kanak-kanak pada aktiviti seni juga melalui tiga tahap iaitu:-
i. Mengamati
ii. Menterjemah
iii. Menilai

Ketiga-tiga dominan ini, mampu memberi pernyataan kendiri secara kreatif, memberi lebih keyakinan diri serta integrasi individu dalam kalangan kanak-kanak. Justeru, kegiatan seni seperti aktiviti melukis ternyata baik untuk meningkatkan keyakinan diri kanak-kanak.

Nor Hashima \& Yahya Che Lah (2003), guru memainkan peranan penting bagi membina kreativiti kanak-kanak, memberi motivasi dan mencipta suasana. Sikap guru adalah salah satu faktor yang diperlukan bagi meransangkan kreativiti. Guru seharusnya:

i. Menghargai idea dan soalan kanak-kanak

ii. Menggalakkan kanak-kanak bercakap atau bercerita

iii. Memberikan komen ikhlas

iv. Memahami kanak-kanak

v. Memberi pandangan yang menggembirakan kepada hasil kerja mereka

vi. Mewujudkan suasana menggalakkan

vii. Merancangkan aktiviti berkualiti dengan menggunakan bahan yang mudah diperoleh dan selamat digunakan

viii. Mendisiplinkan kanak-kanak dengan memberi arahan yang jelas dan betul semasa hendak menggunakan alat-alat

ix. Menggalakkan kanak-kanak bekerjasama antara satu sama lain.

Mereka turut menambah dengan mengetengahkan fungsi seni dalam kegiatan kanak-kanak seperti berikut:-

- Menyediakan peluang untuk kanak-kanak melahirkan dan menyatakan fikiran

- Memberi peluang untuk menyatakan, memperhalusi dan membentuk emosi

- Menyediakan peluang untuk kanak-kanak membentuk kemahiran-kemahiran sosial dan sensitiviti pada manusia dan persekitaran

- Meransang kreativiti dan imaginasi kanak-kanak

- Mengayakan perkembangan bahasa

- Merupakan asas memahami matematik

- Menggalakkan perkembangan kemahiran manipulatif

- Memberikan peluang menyelidik dan menikmati bahan-bahan semula jadi.

- Membina kekuatan otot dan koordinasi

- Mendedahkan penggunaan simbol dan corak yang merupakan persediaan pembacaan dan penulisan

- Melatih penggunaan dan koordinasi tangan dan mata sebagai persediaan menulis dan membaca

- Tindak balas kepada keperluan kanak-kanak untuk mengetahui sesuatu melalui deria: memerhati, memadan, perkembangan intelektual.

- Melatih kanak-kanak memberi tumpuan, mengaitkan kerja ataupun hasil kerja dengan topik lain. 


\section{Beberapa teori yang dapat menyumbangkan kepada pendidikan kanak-kanak yang berkaitan dengan aktiviti seni}

Teori maturationis menekankan kesediaan dan kematangan kanak-kanak. Maka aktiviti-aktiviti yang dirancang oleh guru haruslah dapat membantu perkembangan dan pencapaian kanak-kanak. Seseorang guru seharusnya menyediakan aktiviti-aktiviti pendidikan dan menggalakan pembelajaran sosial. Bersoon (1982), menyatakan galakan yang diberi kepada kanak-kanak menggunakan deria dan respon emosinya dalam memperoleh pengalaman yang disediakan menerusi kegiatan seni akan meningkatkan keupayaan kanak-kanak dalam membuat pengamatan dan pentaksiran. Bowen (1980), mendapati bahawa pengamatan kanak-kanak dalam memerhati ketika melukis atau membuat lakaran dapat meningkatkan kebolehan mereka dalam pengamatan dan memperkayakan pengetahuannya tentang perbezaan setiap objek atau imej tampak di sekeliling mereka. Jika kanak-kanak diberi pendedahan kaedah dan teknik yang sempurna, mereka akan berupaya mengembangkan pemikiran yang kritis.

Teori kognitif merujuk kepada proses mental yang aktif untuk mendapatkan ilmu, menyimpan, meningkat ilmu dan menggunakan ilmu. Cara individu berfikir tentang situasi termasuklah kepercayaannya, jangkaannya dan perasaannya mempengaruhi fakta yang individu pelajari dan cara dia belajar (Ramlah Jantan \& Mahani Razali, 2002).

Pendekatan kognitif mementingkan tingkah laku yang dimotivasikan oleh naluri ingin tahu dan desakan mencuba manusia. Tingkah laku dipengaruhi oleh cara seseorang mengamati persekitarannya untuk mencari penyelesaian atau menguasai kemahiran. Ini bermakna dalam pendekatan kognitif, individu didorong oleh motivasi instrinsik (Boon Pong Ying\& Ragbir Kaur, 1998).

Ahli psikologi yang tergolong dalam teori kognitif adalah Jean Piaget, Jerome Bruner, David Ausubel dan Robert Gagne. Model pemprosesan maklumat Gagne merupakan salah satu daripada teori kognitif yang boleh digunakan dalam menghubungkaitkan aktiviti melukis dalam meningkatkan keyakinan diri seseorang. Gagne (1975), dalam bukunya Esentials of Learning for Instruction telah mengemukakan satu teori bagaimana seseorang individu memperoleh maklumat dalam sesuatu proses pembelajaran dan seterusnya daripada maklumat tersebut seseorang individu itu berjaya memanipulasikannya sehingga boleh meningkatkan prestasinya pada masa hadapan (Trawick \&Smith, 2003).

Pengalaman yang bermula dengan penerokaan dan dilanjutkan dengan percubaan yang berperingkat-peringkat akan meyakinkan murid untuk berinteraksi dengan bahan dan pelbagai teknik. Ini secara tidak langsung dapat meningkatkan keyakinan diri, mampu mengimbangi hubungan komunikasi murid dan komunikasi murid terhadap hasil lukisan kanak-kanak.

Jelaslah bahawa seni merupakan asas untuk mengembangkan naluri ingin tahu secara explorsi menerusi deria. Pemikiran kreatif dan kritis akan terus dijana melalui ekspresi diri mereka. Justeru, dalam situasi ini, kajian Eisner (1980), mendapati bahawa kanak-kanak sering berhadapan dengan masalah menggunakan kemampuan dalam membuat huraian dan seterusnya cuba membina satu konsep yang sempurna. Fenomena ini terjadi ketika kanak-kanak membuat pengamatan, membuat tafsiran dan tanggapan seterusnya melahirkan konsep. Oleh itu, aktiviti seni memainkan peranan penting yang tersendiri di peringkat kanak-kanak. 


\section{PERBINCANGAN}

Kebanyakan pengkaji seni kanak-kanak menganggap hasil karya seni sebagai satu kaedah menarik untuk melihat cara kanak-kanak ini berfikir dan menyelami perasaan selain melihat dan menguji keupayaan perkembangan kognitif mereka. Karya seni kanak-kanak adalah bersifat peribadi dan tersendiri. Ini selaras dengan Lowenfeld (1975) yang menyatakan bahawa penghasilan karya terutama lukisan hasil kanak-kanak mempunyai interpretasi yang berbeza dengan karya yang dihasilkan oleh orang dewasa. Bagi orang dewasa, seni visual sering dikaitkan dengan kecantikan dan kesempurnaan, manakala bagi kanak-kanak hasil karya mereka adalah bersifat luaran dan ekspresif.

Tidak dapat dinafikan bahawa setiap kanak-kanak dilahirkan dengan memiliki sifat yang dinamik serta berkembang mengikut fitrah semula jadi proses tumbesaran mereka. Hasil kerja seni visual yang dihasilkan oleh kanak-kanak ini berfungsi sebagai alat komunikasi dan merupakan refleksi pemikiran mereka. Refleksi ini menurut Koster (2001), akan terus berkembang bersama kanak-kanak sehingga mereka membesar.

Jelaslah bahawa pengetahuan asas mengenai lukisan yang dihasilkan oleh kanak-kanak amat penting untuk meningkatkan keyakinan diri mereka sebelum mereka didedahkan dengan pelbagai aktiviti seni yang lain. Justeru guru pendidikan awal kanak-kanak harus merancang aktiviti-aktiviti yang bersesuaian mengikut tahap kemampuan kanak-kanak .

Penglibatan kanak-kanak di dalam aktiviti melukis berupaya memberikan ransangan dan pembangunan dari pelbagai aspek. Pembangunan tahap kreativiti kanak-kanak kecil dapat dipertingkatkan selain mewujudkan rasa sensitiviti mereka terhadap persekitaran. Selaras dengan itu dapat diketengahkan bahawa kepentingan aktiviti melukis kepada kanak-kanak dapat dilihat melalui aspek berikut selaras dengan kepentingan pendidikan seni visual:

a. Aspek Kognitif

Aktiviti melukis dalam kalangan kanak-kanak kecil dapat melahirkan kanak-kanak yang mempunyai keupayaan menyelesaikan masalah serta sedikit sebanyak membantu mereka dalam membuat penilaian dan bijak membuat keputusan.

b. Aspek Fizikal

Dengan menggunakan alat dan bahan dalam pengajaran dan pembelajaran yang bersesuaian, aktiviti melukis dalam kalangan kanak-kanak kecil dapat memberikan satu latihan berkesan kepada otot tangan dan koordinasi tangan serta mata kanak-kanak.

c. Aspek Kreativiti

Aktiviti melukis yang bersifat terbuka dapat membantu kanak-kanak kecil untuk mengembangkan aspek kreativiti mereka. Ini kerana aktiviti yang dilakukan oleh kanakkanak kecil adalah mengutamakan proses, berbanding dengan hasilan akhir. Situasi ini dapat menyuburkan budaya pemikiran kritikal dalam menyelesaikan sesuatu masalah dalam kalangan kanak-kanak kecil. Melalui aktiviti melukis juga mampu menggalakkan eksplorasi dan eksperimentasi dalam kalangan kanak-kanak kecil agar mereka memiliki pengalaman yang luas dalam bidang penghasil karya seni.

d. Aspek Persepsi

Aktiviti melukis dalam kalangan kanak-kanak kecil juga dapat mempertingkatkan dan menajamkan penggunaan pancaindera dan deria kanak-kanak kecil. Ia mampu berhubung 
konsep pembuatan dan kronologi sesuatu produk iaitu proses penghasilan dan hasilan seni, produk dan objek yang terdapat di sekeliling mereka.

e. Aspek Sosial dan Emosi.

Aktiviti melukis dalam kalangan kanak-kanak memberi peluang kepada kanak-kanak kecil ini untuk berinteraksi dan meningkatkan keupayaan bersosial mereka dan seterusnya meningkatkan keyakinan diri. Contohnya semasa aktiviti melukis mereka dapat berinteraksi antara satu sama lain. Ini memberi peluang kepada kanak-kanak untuk saling hormat-menghormati, yang juga merupakan landasan dalam memupuk perasaan bertoleransi dalam diri setiap individu. Keadaan ini dapat mewujudkan semangat bekerja sama di dalam kumpulan yang dibentuk.

Bertitik tolak daripada kepentingan tersebut jelaslah bahawa aktiviti melukis dapat meningkatkan keyakinan diri dalam kalangan kanak-kanak kecil. Ini turut disokong oleh Nani Menon (2003), yang menyatakan bahawa aktiviti seni kreatif seperti melukis dan mewarna dapat memberi peluang kepada kanak-kanak merealisasikan imaginasi mereka di dalam pelbagai cara. Bidang seni kreatif merupakan salah satu cara untuk kanak-kanak untuk melahirkan perasaan secara semulajadi dan kreatif. Aktiviti seni kreatif juga merupakan satu cara untuk mendekatkan kanak-kanak kepada budaya masyarakat Malaysia. Menurut Isernberg (2001) menyatakan seni adalah satu sistem simbol yang boleh digunakan untuk menjana makna dan alat pembelajaran. Ini adalah kerana aktiviti seni kreatif menyediakan ruang untuk kanak-kanak berkomunikasi tanpa bahasa atau dengan bahasa.

Justeru, daya cipta kreativiti kanak-kanak kecil perlu dipertimbangkan dengan memberi kebebasan dalam mencurah atau melahirkan perasaan dan idea yang menggalakkan daya cipta kreativiti seperti aktiviti melukis. Selaras itu, Koster (2001) menyatakan kanak-kanak dilahirkan dengan mempunyai sifat yang dinamik serta berkembang mengikut fitrah semula jadi proses tumbesaran mereka. Hasil kerja seni seperti lukisan berfungsi sebagai alat komunikasi dan merupakan refleksi pemikiran kanak-kanak. Refleksi ini akan terus berkembang bersama kanak-kanak. Penghasilan karya terutama lukisan oleh kanak-kanak kecil mempunyai interpretasi yang berbeza dengan karya yang dihasilkan oleh oleh orang dewasa. Bagi orang dewsasa, hasil karya seni lukisan sering dikaitkan dengan kecantikan dan kesempurnaan tetapi bagi kanak-kanak karya yang dihasilkan bersifat luahan dan ekspresif (Lownfeld, 1975). Justeru, hasil karya seni kanak-kanak adalah satu kaedah yang sangat unik untuk menyelami perasaan selain melihat dan menguji kefahaman kognitif dan seterusnya dapat meningkatkan keyakinan diri mereka untuk berinteraksi dengan alam persekitaran.

Pentingnya aktiviti melukis dalam kalangan kanak-kanak kecil untuk membolehkan mereka tahu potensi kecenderungan diri serta potensi yang tersembunyi dalam diri mereka. Antaranya kepentingan kreativiti kanak-kanak khasnya dalam aktiviti melukis ialah;

- Aktiviti melukis merupakan aktiviti yang membantu kanak-kanak kecil meningkatkan daya sensitiviti terhadap alam sekeliling mereka. Ini kerana proses melukis menjurus ke arah pengamatan terhadap objek dan melatih deria kanak-kanak kecil supaya menjadi lebih peka dan meningkatkan daya persepsi mereka.

- Aktiviti melukis meningkatkan daya imaginatif kanak-kanak kecil selain berupaya mengimbangi semosi mereka. Ia merupakan satu proses pembelajaran kanak-kanak kecil melalui aktiviti peniruan (imitasi) alam sekeliling yang dipermudahkan dan menjadi penghasilan simbol abstrak seterusnya menjadi satu bentuk hasil karya yang unik. 
Pernyataan tersebut, selaras dengan pendapat Lowenfeld (1975) yang mengatakan bahawa hasil karya merupakan kemampuan seseorang menghasilkan sesuatu yang kreatif, baru dan asli.

Sebagai rangkuman menyeluruh, aktiviti melukis dalam kalangan kanak-kanak kecil adalah merupakan sebagai:

a. Medium Komunikasi - sebelum kanak-kanak kecil berupaya untuk bertutur, lukisan adalah merupakan bentuk komunikasi awal mereka di mana ia dijadikan sebagai alat perhubungan yang berkesan untuk kanak-kanak kecil ini berinteraksi. Lukisan juga dijadikan sebagai alat untuk membantu saintis menganalisa fikiran dan perasaan kanakkanak kecil. Penghasilan imej seperti pokok, figura manusia, catan dan arca boleh memberi tafsiran yang dapat membantu ahli psikologi untuk mengenal pasti kanak-kanak kecil yang mempunyai masalah trauma. Ini turut disokong oleh Sternberg (2001) yang menyatakan bahawa sesuatu yang semula jadi dicungkil dan diolah menjadi lebih baik dan kreatif seperti akitiviti melukis. Aktiviti yang kreatif membolehkan kanak-kanak meningkatkan sifat ingin tahu dan ianya merupakan satu cara berkomunikasi dengan dan tanpa bahasa. Daya kreativiti kanak-kanak yang semula jadi sebenarnya melahirkan perasaan kegembiraan, kesedihan dan kekecewaan serta ianya membantu kanak-kanak untuk melahirkan emosi dan perasaan mereka.

\section{b. Cara Mencapai Kepuasan Diri}

Umumnya kanak-kanak kecil belajar sambil bermain, aktiviti bermain memberikan kepuasan selain memberi peluang kepada mereka untuk meneroka alam sekeliling. Seperti bermain, melukis juga merupakan aktiviti yang mampu memberikan kepuasan diri kepada kanak-kanak kecil. Melalui lukisan, kanak-kanak kecil dapat meluahkan perasaan dan emosi mereka selain dapat membina kekuatan otot. Aktiviti seperti ini dapat membantu menajamkan daya intuisi kanak-kanak kecil. Selaras itu, teori perkembangan artistik Al Hurwitz dan Day (2001) adalah berkaitan yang menyatakan bahawa lukisan yang dihasilkan oleh kanak-kanak adalah tidak terkawal walaupun lukisan mereka lebih merupakan contengan. Lukisan ini lebih bergantung pada keupayaan otot dan keselarasan koordinasi mata dan tangan kanak-kanak. Peringkat ini berkembang secara progresif dalam lingkungan umur 2-4 tahun.

\section{c. Meningkatkan Daya Penguasaan Kendiri}

Aktiviti melukis dapat memberikan kepuasan kepada kanak-kanak kecil dalam meluahkan apa yang mereka lihat. Lukisan akan dipindahkan semula mengikut tahap pemahaman kanak-kanak kecil ini yang secara tidak langsung mampu membentuk personaliti mereka. Konsep kendiri terbina apabila kanak-kanak kecil mampu melukis tanpa ragu dan mereka tidak rasa bimbang sama ada hasil karya mereka cantik atau sebaliknya. Kanak-kanak kecil ini akan bercerita mengenai hasil lukisan mereka dan ini membantu untuk mereka membina keyakinan diri untuk bertutur dan berinteraksi dengan rakan sebaya, guru dan seterusnya pada masyarakat umum. Keadaan ini berkait rapat dengan teori perkembangan Artistik Luquet (2001), bahawa lukisan contengan kanak-kanak telah membentuk imej dan objek yang hampir sama dengan objek sebenar dengan melukisnya berulang kali kerana wujudnya keyakinan diri.

Berdasarkan huraian tersebut, jelaslah bahawa melalui aktiviti melukis dalam kalangan kanakkanak kecil adalah sangat penting dalam menyumbang kepada perkembangan kognitif, psikomotor dan afektif kanak-kanak kecil. Dengan kombinasi tersebut luikisan mampu meningkatkan keyakinan diri dalam kalangan kanak-kanak kecil. Ini disebabkan kanak-kanak kecil dilahirkan dengan keperluan dan 
keinginan untuk mengetahui dunia sekeliling mereka, mereka boleh menghubungkaitkan aktiviti melukis dengan perasaan, intuisi dan kreativiti yang mampu membangunkan keupayaan mereka untuk menjadi insan yang kreatif dan imaginatif. Melalui aktiviti melukis juga mampu menyumbang kepada keseimbangan jasmani, emosi, rohani, intelek dan sosial dalam kalangan kanak-kanak kecil selaras dengan falsafah pendidikan Malaysia.

Justeru, keyakinan diri kanak-kanak kecil ini akan lebih mantap kerana dapat meluahkan perasaan mereka dalam bentuk lukisan. Ini turut disokong dengan Teori oleh tokoh-tokoh seni visual seperti Victor Lowenfeld, Hurtwitz dan Day. Lukisan adalah dianggap sebagai medium untuk berkomunikasi dan melahirkan idea dan perasaan. Bagi kanak-kanak, pendedahan awal dapat mengembangkan daya kreativiti dengan meningkatkan daya ekspresi, intuisi, imaginasi dan konsepsi mereka.

\section{CADANGAN}

Tahap keperluan asas kanak-kanak kecil harus diambil kira selaras dengan Teori Heiraki Keperluan Maslow yang menyatakan bahawa dalam diri setiap indvidu terdapat lima (5) keperluan yang perlu dipenuhi seperti fisiologi, keselamatan, sosial, penghargaan diri dan pencapaian hasrat diri. Bila satu keperluan dicapai, keperluan yang seterusnya akan menjadi satu keperluan atau keutamaan seterusnya. Setiap individu akan memastikan tahap keperluan terendah dipenuhi terlebih dahulu sebelum berusaha untuk memenuhi keperluan tahap yang lebih tinggi.

Justeru, pendidikan seni termasuklah aktiviti melukis tergantung kepada setakat mana keperluan-keperluan kanak-kanak kecil dipenuhi dalam proses pengajaran dan pembelajaran. Justeru, sebagai cadangan, guru harus mempertimbangkan perkara-perkara berikut:

- Mewujudkan suasana bilik darjah yang kondusif. Misalnya dari segi susunan fizikal bilik darjah seperti meja dan kerusi, ruang dan saiz bilik darjah, kemudahan, bilik darjah, hubungan guru-murid dan sudut pameran hasil karya lukisan.

- Memastikan keperluan asas kanak-kanak kecil telah dipenuhi terlebih dahulu seperti keperluan fisiologi iaitu makanan, minuman dan tempat tinggal agar mereka dapat fokus untuk belajar.

- Mengamalkan sifat penyayang kepada kanak-kanak kecil bagi memenuhi keperluan dan kasih sayang kanak-kanak kecil dalam bilik darjah. Guru juga harus bersikap adil terhadap semua kanak-kanak kecil di bawah bimbingannya agar kanak-kanak kecil ini rasa dihargai dan mampu mendorong motivasi mereka untuk belajar khususnya dalam menghasilkan karya seni seperti lukisan.

- Merancang aktiviti pengajaran dan pembelajaran berdasarkan kebolehan pelajar. Misalnya mengikut tahap kemampuan pelajar dan harus diselaraskan dengan aktiviti lukisan yang bersesuaian.

- Sentiasa memupukkan nilai-nilai penghargaan kendiri dalam kalangan kanak-kanak kecil di samping berterusan memberi motivasi dan peneguhan yang bersesuaian.

- Memupuk nilai-nilai motivasi diri melalui bimbingan agar kanak-kanak kecil mampu memahami diri, menerima diri dan melibatkan diri secara aktif dalam pelbagai aktiviti pengajaran dan pembelajaran dalam bilik darjah.

Manakala kombinasi jasmani, emosi, rohani, intelek dan sosial amat penting untuk memberi keseimbangan pada diri pelajar. Dari segi perkembangan jasmani, pergerakan otot-otot mereka ketika memegang pensel dan bahan lukisan, perlakuan mencampur warna dan sebagainya akan menjadi sebati 
melalui latihan aktiviti-aktiviti melukis. Justeru, latih tubi dalam aktiviti melukis ini mampu membina keyakinan dirinya diri dalam kalangan kanak-kanak kecil untuk membina keyakinan diri.

Sementara, emosi yang stabil mampu memberi gerak balas yang positif di mana semakin usia kanak-kanak kecil ini meningkat maka emosi mereka menjadi semakin stabil. Misalnya kanak-kanak kecil yang mengikuti aktiviti melukis memerlukan emosi yang stabil untuk menghasilkan karya dalam meluahkan perasan mereka. Untuk itu guru perlu membuat penyesuaian dengan bentuk-bentuk emosi kanak-kanak kecil yang diinginkan bagi membina keyakinan diri mereka.

Dengan memperbanyakkan aktiviti-aktiviti yang melibatkan kerohanian dan moral, guru mampu membentuk rohani yang seimbang dalam kalangan kanak-kanak kecil yang dibimbing. Misalnya dalam aktiviti melukis, kanak-kanak dapat melakar lukisan yang bertemakan kasih sayang 'ibu bapa sayang anak', lakaran lukisan 'tangan bersalaman' dan sebagainya. Aktiviti seperti ini mampu membantu kanak-kanak menghargai sesuatu atau seseorang dan seterusnya mampu meningkatkan keyakinan diri mereka yang diluahkan melalui lakaran lukisan.

Dari aspek intelek pula, dalam aktiviti melukis kanak-kanak kecil belajar menguasai konsep paduan. Ini bermaksud penggunaan warna yang pelbagai merupakan satu kesepaduan untuk kanakkanak ini melengkapkan lukisan mereka dari segi mewarnakan lukisan yang berwarna-warni. Pada peringkat ini juga mereka dapat menguasai pertuturan dan gemar membaca. Melalui aktiviti lukisan kanak-kanak kecil mampu menceritakan semula apa yang telah dilukis mereka untuk dijadikan satu cerita. Kanak-kanak kecil ini juga akan mampu mempertingkatkan rasa bertambah yakin dalam diri mereka kerana lakaran lukisan tersebut dijadikan sebagai satu landasan untuk mereka membina satu cerita.

Manakala dari segi sosial pula, peranan keluarga, sekolah dan masyarakat sangat penting dalam membentuk sosial dan sahsiah kanak-kanak kecil. Mengikut teori Bandura (1986), elemen sosial dalam aktiviti melukis dalam kalangan kanak-kanak kecil ini akan wujud apabila pembelajaran yang diperolehi membabitkan perlakuan-perlakuan melihat, meniru dan memerhati tingkah laku orang lain. Teori ini juga dikenali sebagai teori pemerhatian atau teori peniruan. Misalnya gambar rumah beratap rumbia, kanak-kanak kecil mampu melukisnya semula dengan yakin lukisan rumah beratap rumbia sekiranya mereka pernah melihatnya sebelum ini. Melalui lakaran lukisan seumpama itu akan mempertingkatkan keyakinan diri dalam kalangan kanak-kanak kecil ini.

Berdasarkan huraian tersebut di atas, jelaslah bahawa strategi pengajaran guru amat mempengaruhi dalam aktiviti lukisan untuk meningkatkan keyakinan diri dalam kalangan kanak-kanak kecil. Latihanlatihan perlu diperbanyakkan agar kanak-kanak kecil ini memiliki keyakinan diri yang lebih baik kerana secara tidak langsung mereka akan mampu berinteraksi, bertutur, meluah perasaan, menghormati dan sebagainya yang diluahkan melalui karya lukisannya.

\section{PENUTUP}

Kanak-kanak merupakan seorang insan cilik yang sinonim dengan kegiatan seni kreatif dalam kehidupan mereka. Kebanyakan mereka sangat berminat dengan aktiviti seni kreatif seperti melukis. Aktiviti ini memberi peluang kepada kanak-kanak merealisasikan imaginasi mereka di dalam pelbagai cara. Dengan melakukan aktiviti melukis membolehkan kanak-kanak kecil untuk meluahkan keinginan dan keperluan mereka untuk membina keyakinan diri. Mereka dapat membina pengalaman baru hasil daripada penerokaan dalam kehidupan dan akan berasa seronok apabila mencipta sesuatu yang baru. Misalnya dalam aktiviti melukis, mereka dapat melukis sesuatu benda baru yang merupakan idaman 
mereka seperti 'rumah idamanku' dengan melukis pelbagai jenis dan bentuk rumah yang cantik. Mereka meluahkan rasa hati, mereka mencipta sesuatu lukisan dengan menggunakan cara tersendiri yang mencerminkan kreativiti dan seterusnya membina keyakinan diri mereka. Di samping itu, guru akan memberi peluang kepada kanak-kanak kecil untuk bercerita dan berkongsi pengalaman dengan rakan sebaya mereka tanpa rasa segan dan ragu-ragu. Ia mengukuhkan lagi keyakinan diri mereka untuk berhadapan dengan dunia luar kelak.

\section{RUJUKAN}

Amabile. (1992). Growing Up Creative. Nurturing a Lifetime of Creativity. New York: The Creative Education Foundation.

Amabile. (1992). Swartz 1989, Buzan 2002, de Bono 1971, Leong 1998).

Bandura, A. (1986). Social foundations of thought and action. A social cognitive theory. Englewood Cliffs. NJ: Prentice -Hall, Inc.

Boon Pong Ying\& Ragbir Kaur. (1998). Psikologi II (semester III) .Shah Alam: Fajar Bakti Sdn.Bhd.

Buzan, Tony. (2002). The power of creative intelligence. London: Thorsons

Champman, L. (1978). Recent trends and problems in art education. Encyclopedia of education. New York: Macmillan Co.

Cropley.J.A. (2001). Creativity in education \& learning. London: Kogan Page.

De Bono, Eward. (1996). Serious creativity. London: Harper Collins Business.

Day.M. \& al Hurwitz. (2001). Children and their art: methods for the elementary school. Texas: Harcout College

Donald W.Mac Kinnon .2005. IPAR's Contributions to the conceptualization and study of creativity. Perspectives in creativity. Taylor, IA \& Getzels, J.W. (Eds). Chicago, IL: Aldine Publishing Company.

Efland, Arthur. (1977). Planning art education. Middle/Secondary School of Ohio: State of Ohio Dept. of Education.

Eisner, E. W. (1980). Educating artistic vision. New York: Macmillan Co.

Gardner, H. (1985). The unschool mind: How children think and how schools should teach. Educational Researchers, 18(8), 4-10.

Koster, J. B. (2001). Bringing art into the elementary classroom. Belmont, CA: Wadsworth.

Luquet, G.H. (2001). Children's drawing. London: Alan Costal.

Lowenfeld, V. \& Brittain, W.L. (1975). Creative and mental growth. New York: Macmillan Co.

Michael, J. A. (1983). Art and adolenssence-teaching art at the secondary school level. New York: Teachers College Press.

Nani Menon. (2003). Panduan mengembangkan daya fikir kanal-kanak prasekolah/ Nani Menon \& Rohani Abdullah. Bentong, Pahang: PTS Publications \& Distributior Sdn.Bhd.

Nor Hashima \& Yahya Che Lah. (2003). Panduan pendidikan prasekolah. Bentong: Pahang. PTS Publication \& Distributors Sdn. Bhd.

Ramlah Jantan, Mahani Razali. (2002). Psikologi pendidikan: Pendekatan kontemporari. Kuala Lumpur: McGraw-Hill Malaysia.

Sternberg, R. J. (2001). Teaching psychology students that creativity is a decision. The General Psychologist, $36(1), 8-11$.

Trawick \&Smith. (2003). Early childhood development: A multicultural perspective. Prentice Hall.

Victor Lownfeld dan Brittain. (1986). Creative and mental growth. New York: Macmilan. 